\title{
Desenvolvimento da subjetividade: análise de histórias de superação das dificuldades de aprendizagem
}

\author{
Maristela Rossato \\ Universidade de Brasília - DF \\ Albertina Mitjáns Martínez \\ Universidade de Brasília - DF
}

\begin{abstract}
Resumo
Este artigo discute a subjetividade numa perspectiva sistêmica e processual, orientado pela Teoria da Subjetividade desenvolvida por González Rey, analisada na trajetória escolar de estudantes identificados com dificuldades de aprendizagem. Tem por objetivo analisar como ocorre o movimento da subjetividade no processo de superação das dificuldades de aprendizagem escolar. A pesquisa foi realizada com três estudantes dos anos iniciais do Ensino Fundamental, por meio de Estudo de Caso Múltiplo. Foram utilizados sistemas conversacionais, instrumentos apoiados em indutores escritos e indutores não escritos, momentos informais, análise documental e observações no ambiente escolar. Concluímos que a superação das dificuldades de aprendizagem pode se dar pelo reconhecimento do sujeito no estudante, pela vivência de condições favorecedoras à produção de sentidos subjetivos e pela reconfiguração de elementos da subjetividade do estudante. Essas reflexões deram sustentação para definirmos o desenvolvimento da subjetividade como mudanças subjetivas que impactam, ganham certa estabilidade e são capazes de desencadear outras mudanças, gerando novos níveis qualitativos de organização subjetiva.
\end{abstract}

Palavras-chave: Subjetividade, distúrbios de aprendizagem, desenvolvimento.

\section{Subjectivity development: analyzing histories of overcoming learning difficulties}

\begin{abstract}
In this article we discuss the subjectivity from a systemic and processing perspective, under the Theory of Subjectivity developed by González Rey , analyzed in the educational trajectory of students identified with learning difficulties. Our goal is to analyze how the movement of subjectivity occurs in the processes of overcoming school learning difficulties. The research was conducted with three students from the early years of elementary school, through Multiple Case Study. We used conversational systems, instruments supported by written and unwritten inductors, informal moments, document analysis and observations in the school environment. We conclude that overcoming learning difficulties can be attained by the recognition of the student as subject, by the experiencing of conditions in favor of subjective sense production and by the reconfiguration of elements of subjectivity in students. These reflections may give support to define the development of subjectivity and subjective changes that impact and gain some stability, capable of triggering other changes, creating new levels of qualitative subjective organization.
\end{abstract}

Keywords: Subjectivity, learning disabilities, development.

\section{Desarrollo de la subjetividad: análisis de historias de superación de dificultades de aprendizaje}

\begin{abstract}
Resumen
Este artículo discute la subjetividad analizada en la trayectoria escolar de estudiantes identificados con dificultades de aprendizaje bajo perspectiva sistémica y procesal, orientado por la Teoría de la Subjetividad desarrollada por González Rey. Tiene como objetivo analizar como ocurre el movimiento de la subjetividad en el proceso de superación de las dificultades de aprendizaje escolar. La investigación se realizó con tres estudiantes de los primeros años de la Enseñanza Básica a través del Estudio de Caso Múltiplo. Se utilizaron sistemas conversacionales, instrumentos respaldados en inductores escritos e inductores no escritos, momentos informales, análisis documental y observaciones en ambiente escolar. Las conclusiones indican que la superación de las dificultades de aprendizaje puede suceder debido al reconocimiento del sujeto en el estudiante, por vivir condiciones favorecedoras de producción de sentidos subjetivos y por la reconfiguración de elementos de la subjetividad del estudiante. Estas reflexiones ofrecen subsidios para definir el desarrollo de la subjetividad como cambios subjetivos que impactan y que adquieren cierta estabilidad, capaces de desencadenar otros cambios, generando nuevos niveles cualitativos de organización subjetiva. Palabras clave: Subjetividad, trastornos del aprendizaje, desarrollo.
\end{abstract}




\section{Introdução}

Compreender as fronteiras entre mudança e desenvolvimento da subjetividade requer um olhar sensível do pesquisador, amparado por um rigor teórico que lhe possibilite produzir inteligibilidade em meio à complexidade humana e seus processos evolutivos. As discussões apresentadas neste artigo são decorrentes de uma pesquisa realizada com estudantes das séries iniciais do ensino fundamental que teve por objetivo compreender como a subjetividade do estudante se movimenta no processo de superação das dificuldades de aprendizagem escolar.

As dificuldades de aprendizagem são apontadas pela escola quando o estudante não consegue cumprir as exigências das características que assumem os processos de ensinar e aprender sem, na maioria dos casos, considerar a multiplicidade de fatores - inclusive da própria escola - que podem estar no entorno do problema (Rossato \& Mitjáns Martínez, 2011). Mais do que compreender como esses julgamentos são construídos e seus impactos no processo de ensinar e aprender, a pesquisa perseguiu casos de estudantes que, da mesma forma que foram apontados com dificuldades, foram reconhecidos pela escola por terem-nas superado. Os processos envolvidos na superação das dificuldades de aprendizagem foram investigados e analisados no movimento da subjetividade dos estudantes, considerando as ações, as relações e as concepções envolvidas na produção dos sentidos subjetivos em diferentes momentos da pesquisa.

Vale destacar que não foi realizado nenhum trabalho que envolvesse supostos processos cognitivos relacionados às dificuldades apontadas pela escola, ou seja, não houve, nem da parte da escola, nem da parte das pesquisadoras, ação interventiva com objetivo de superar as dificuldades. A superação das dificuldades de aprendizagem resultou das mudanças ocorridas na organização da subjetividade dos estudantes, mobilizada por fatores diversos, como veremos no decorrer do artigo. A metodologia utilizada na pesquisa possibilitou analisar a subjetividade dos estudantes em diferentes momentos, permitindo que comparações entre os momentos inicial, intermediário e final fossem feitas. Somente com uma compreensão da subjetividade como um sistema complexo, submetido permanentemente à tensão das rupturas ou das criações que tornam sua expressão imprevisível, transcendendo as representações estático-descritivas da psique, uma pesquisa dessa natureza pôde ser realizada.

A Teoria da Subjetividade de González Rey (1995, 2003a, 2003b) constituiu a base teórica da pesquisa por ser, em essência, uma teoria que busca compreender a subjetividade reconhecendo o valor da história e da cultura, possibilitando, com isso, olhar o estudante em seus processos singulares. Mais especificamente, a teoria citada permitiu: (a) compreensão da subjetividade como sistema complexo, dinâmico e em permanente mobilidade; (b) concepção do sujeito que ensina e que aprende constituído na inter-relação tensa e contraditória entre a subjetividade individual e a subjetividade social; (c) produção contínua de novos sentidos subjetivos capazes de entrar no sistema de configurações subjetivas; (d) possibilidades de reconfiguração subjetiva e mudanças nos núcleos das configurações subjetivas.

A relação complexa e dinâmica entre o social e o individual é uma das marcas que a distinguem de outras teorias que abordam a subjetividade. A subjetividade social existe em inter-relação com a subjetividade individual, sem que a primeira represente a soma da segunda, permitindo compreender a dimensão subjetiva - sentidos subjetivos e configurações subjetivas - dos processos e instituições sociais, nos diferentes contextos e momentos históricos em que se organiza, desentranhando os processos geradores das configurações subjetivas dos grupos sociais e o modo como estes se presentificam nos processos individuais. A subjetividade individual se organiza em torno de elementos essenciais na sua compreensão e desenvolvimento: o sujeito e a personalidade que interagem numa relação em que um é momento constituinte do outro sem que seja diluído por ele. O reconhecimento do caráter ativo, gerador, reflexivo e criativo do sujeito coloca a relação com o social em permanente estado de tensão e rupturas, podendo gerar novas unidades de subjetivação individual e social. Já a personalidade, é considerada, nessa abordagem teórica, como um sistema subjetivo auto-organizador da experiência constituída na história do sujeito, um sistema de configuração de configurações. Por ser um sistema autônomo, possui a plasticidade que lhe permite mudanças contínuas por meio da configuração entre o histórico e o atual, revelando-se também gerador de sentidos na história do sujeito. As configurações subjetivas são formas complexas de organização dos sentidos subjetivos produzidos nos processos de subjetivação individual e social, tendo caráter organizador e, ao mesmo tempo, gerador dos sentidos subjetivos, que são produções dos sujeitos resultantes dos desdobramentos simbólico-emocionais produzidos em nível individual, mas também pelas unidades sociais que atuam nos espaços da subjetividade social (González Rey, 2003a).

Desenvolvimento e mudança da subjetividade foram tomados na pesquisa por meio de algumas especificidades. O conceito de mudança presente na Teoria da Subjetividade de González Rey foi analisado a partir da conceituação de circuito tetralógico proposta por Morin, Ciurama e Motta (2003) - ordem-desordem-interações/reencontros-organização - estabelecendo, com isso, uma dinâmica mutacional de impactos no sistema, mesmo que sejam de superfície. A representação proposta pelo autor direciona o olhar para uma mudança que contém em si uma perspectiva que se distingue do olhar linear e vertical, mas a concebe processualmente, de forma que início e fim constituem partes integrantes do mesmo processo. As interações/reencontros se relacionam tanto com a ordem e a desordem quanto com a organização, na qual estaria uma nova ordem que é provocadora de desordens. Morin (2003a) define esse processo com a ideia de circuito, que pode ser definido como uma sucessão de fenômenos periódicos - sentido em que organização não significa cada coisa em seu lugar, mas um sistema em movimento. O caráter organizador dos sentidos subjetivos 
atribuído às configurações subjetivas, como vimos anteriormente, expõe a profunda mobilidade que inerentemente caracteriza o sistema de configurações, mais conhecido como personalidade. A organização contém em si o princípio de unidade complexa, "ela deve ser pensada de maneira não reducionista, mas articuladora, não simplificante, mas multirramificada; ela comporta de maneira nuclear as ideias de reciprocidade, de ação e de retroação" (Morin, 2003b).

Essa relação tetralógica e sistêmica possui em si mesma um caráter original, pois, quanto mais complexa se torna a organização, mais a ordem se mistura à desordem, provocando os acasos e antagonismos e tornando a ordem das organizações frágeis, relativas, perecíveis, mas também evolutivas e construtivas. A desordem está presente na organização de forma potencial e ativa, possibilitando a emergência do novo, da mudança. "A desordem não é perseguida pela organização: ela é ali transformada, permanece virtualizada, pode se atualizar, prepara em segredo sua vitória" (Morin, 2003b, p. 166). Ordem, desordem e organização se coproduzem de forma simultânea e recíproca nas interações e reencontros, característicos dos processos de mudanças.

Nesse sentido, organização implica em mudanças, conquanto estas não garantam o desenvolvimento da subjetividade, já que são geradas pelo caráter organizador das configurações. Essa não causalidade entre mudança e desenvolvimento pode ser identificada também em nível macro, como na política, economia, educação, em diversos setores da sociedade nos quais mudanças são propostas e efetivadas a todo o momento sem que promovam o desenvolvimento dos sistemas - político, econômico, educacional - tanto que muitos problemas tornaram-se historicamente crônicos, embora mudanças estejam continuamente sendo promovidas. O grande desafio contido nesse conjunto de reflexões apresentado até aqui está em conhecer as circunstâncias e as características das mudanças que teriam natureza desenvolvimental.

O desenvolvimento de um sistema (subjetividade) ocorre por forças que incluem o funcionamento do próprio sistema (González Rey, 1995; Morin, 2003a). Considera-se, então, que no funcionamento dos sistemas o foco de análise está na estrutura organizacional, e quanto maior sua complexidade, mais ordem e desordem tendem a estar intimamente ligadas. No caso de desenvolvimento, o foco de análise está na complexidade do processo de mudança desse sistema, pois, como já foi afirmado, nem todas as mudanças promovem desenvolvimento.

González Rey (1995, 2004a, 2007, 2008) considera que o desenvolvimento é singular, processual e holístico, e resulta da integração dos sentidos subjetivos produzidos de forma viva, dinâmica e contraditória nas várias esferas da vida do sujeito e no confronto entre a subjetividade individual e a subjetividade social. As considerações anteriores intensificam uma particularidade do desenvolvimento da subjetividade: o desenvolvimento da subjetividade acontece quando distintos processos de subjetivação - subjetividade social, personalidade, sujeito - são capazes de integrar-se de forma recíproca, ou seja, quando é possível analisar a subjetividade social, a personalidade e o sujeito de forma individualizada e relativamente independente; mas para uma análise do desenvolvimento da subjetividade é necessário adentrar no movimento que um é capaz de promover no outro.

\section{Método}

González Rey (2002, 2003a, 2005) desenvolveu o que denomina Epistemologia Qualitativa como possibilidade para a pesquisa da subjetividade na forma como a concebe, pois, do contrário, não seria possível estudá-la como sistema complexo e histórico em processo contínuo de mobilidade. A expressão cunhada por González Rey Epistemologia Qualitativa conduz a outra compreensão do qualitativo, desde sua base epistemológica, e para isso o autor busca referências no marxismo, na epistemologia histórica francesa, na teoria da complexidade, nos trabalhos de P. Feyerabend, entre outros (González Rey, 2004b). O qualitativo, aqui, está longe das definições tradicionais, como forma de explicar o quantitativo, e caminha no sentido de gerar explicações para os processos que não são diretamente acessíveis pela experiência nem podem ser fragmentados em variáveis ou controlados.

Os aspectos centrais da definição da Epistemologia Qualitativa são: a) o caráter construtivo-interpretativo da produção do conhecimento; b) a pesquisa como processo de comunicação e diálogo; c) legitimação do singular como instância de produção do conhecimento científico.

O caráter construtivo-interpretativo da produção do conhecimento coloca o conhecimento como uma produção do pesquisador a partir do conjunto das informações produzidas na pesquisa, e não como apropriação da realidade. Essa forma de trabalhar com o conhecimento coloca-o na condição de permanente construção, como resultado da produção humana, uma vez que a realidade não é um sistema meramente externo.

$\mathrm{Na}$ pesquisa como um processo de comunicação e diálogo a ênfase na comunicação está centrada no fato de esta permear grande parte dos problemas de natureza social e humana. A comunicação é a via que pode converter os participantes em sujeitos envolvidos com o problema investigado a partir de seus interesses, desejos e contradições. O estabelecimento de uma relação dialógica entre os participantes da pesquisa e o pesquisador permite a abertura de uma via comunicacional em que fluam melhor as informações que os sujeitos podem prestar.

A legitimação do singular como instância de produção do conhecimento científico fundamenta-se na intensa valorização atribuída ao aspecto teórico na pesquisa, que aqui não é compreendido como uma contraposição ao empírico, mas como a construção permanente de modelos de inteligibilidade que deem suporte ao processo de construção do conhecimento.

Na Epistemologia Qualitativa a análise das informações é realizada desde as primeiras atividades de pesquisa, 
uma vez que é responsável por gerar novas demandas de instrumentos e investigações que serão confrontadas com as anteriores, consolidando e abrindo novos caminhos investigativos. Trata-se da análise das informações formais e informais que vão se configurando desde os primeiros movimentos do pesquisador, rompendo com a dicotomia teórico e empírico e considerando o conhecimento como uma produção humana. A análise das informações por meio do princípio construtivo-interpretativo é processual e faz parte de todos os momentos da pesquisa, visando ao desenvolvimento de modelos teóricos capazes de expressar e sistematizar as informações. A construção de modelos teóricos é influenciada pela teoria geral do pesquisador sobre o tema estudado, mas se traduz como sua própria produção. Os modelos teóricos podem ser considerados como a gênese de uma teoria na qual são integrados novos elementos relativos ao problema estudado.

$\mathrm{Na}$ Epistemologia Qualitativa a informação não é considerada em si mesma, mas é algo que pode ser convertido em indicador do sistema subjetivo que envolve o participante da pesquisa ou os espaços e instituições onde se encontra inserido. Essa é uma característica dessa forma de pesquisa qualitativa pela qual uma informação, além de não ter valor em si mesmo, pode desconstruir análises já consolidadas, exigindo a retomada do processo. Isso expressa o caráter construtivo-interpretativo da produção do conhecimento "como um processo de consistência interna, regulado por suas próprias necessidades, em que o papel ativo do pesquisador ocupa lugar essencial" (González Rey, 2002, p. 127).

\section{Participantes}

Os participantes da pesquisa eram de uma escola pública que atende estudantes do $1^{\circ}$ ao $5^{\circ}$ ano do Ensino Fundamental, localizada no Plano Piloto, Brasília-DF. A escola recebia estudantes moradores das quadras próximas à escola e estudantes moradores de regiões administrativas situadas fora do Plano Piloto que, em sua maioria, são filhos de pessoas que trabalham nas quadras próximas da escola. Este local foi escolhido por indicação de uma das equipes especializadas $^{1}$ da Secretaria de Educação do DF. De acordo com a equipe, na escola indicada havia uma concentração significativa de estudantes que "não eram moradores das quadras" e que apresentavam muitas dificuldades de aprendizagem, representando um diferencial em relação às demais escolas do Plano Piloto.

Os professores que atuavam nessa escola eram, em sua maioria, efetivos da Secretaria de Educação, com carga horária de 36 horas semanais. Destas 36 horas, onze eram reservadas para a coordenação pedagógica, como um tempo em que podiam estudar, participar de reuniões, cursos,

\footnotetext{
1 Estas equipes eram formadas por: Orientador Educacional, Professor Classe A com formação em Pedagogia, Professor Classe A, com formação em Psicologia, Professor de Psicologia Classe A ou Analista de Educação com formação em Psicologia.
}

encontros pedagógicos e preparar suas aulas em conjunto com outros professores. Aos estudantes eram oferecidas cinco horas diárias de aula, além das atividades promovidas pela Escola-Parque (atividades artísticas, culturais, esportivas) no contraturno do horário de frequência à Escola Classe.

A pesquisa foi desenvolvida por meio de estudo de caso múltiplo com três estudantes dos anos iniciais do Ensino Fundamental que, conforme relato inicial dos professores, possuíam histórias de múltiplas repetências e eram reconhecidos na escola como estudantes com dificuldades de aprendizagem escolar ${ }^{2}$ sem que houvesse, nesse momento, questionamentos quanto à complexidade que envolve essa expressão. A pesquisa foi realizada em três momentos distintos: no início da pesquisa, com todos os estudantes indicados pela escola com dificuldades de aprendizagem; após seis meses, com cinco desses estudantes que haviam apresentado melhora na qualidade de aprendizagem, conforme resultado das avaliações realizadas pelos professores; e após o transcurso de mais seis meses, com apenas três estudantes (dois mudaram de cidade e não puderam continuar no grupo), para identificar a estabilidade que as mudanças tinham assumido. A seguir uma descrição dos três participantes da pesquisa (nomes fictícios), com informações sobre as respectivas trajetórias escolares.

Conforme documentação escolar, João ingressou na primeira série em 2004, com sete anos, no Nordeste do Brasil, onde morava com parentes, e, na metade do ano de 2005 , estando na segunda série, veio para Brasília, para morar com sua mãe e padrasto. Na ocasião a escola resolveu colocá-lo como ouvinte na primeira série, por julgar que não apresentava condições de acompanhar a série em que estava matriculado. Cursou por dois anos seguidos a $2^{a}$ série. Em 2008 frequentou a terceira série, e em 2009, com 12 anos de idade, cursou a quarta série ${ }^{3}$. Em 2007 foi encaminhado pela professora para a equipe multidisciplinar da SEED/GDF, com o objetivo de realizar avaliação diagnóstica, por suspeita de TDAH. As suspeitas não foram confirmadas, evidenciando-se que sua capacidade intelectual encontrava-se acima da média para o grupo de sua faixa etária (Relatório de Encaminhamento). Em Brasília, esteve em todos os anos matriculado na escola onde a pesquisa foi realizada, por ser próxima do local de trabalho de sua mãe, deslocando-se todos os dias da região do entorno para o Plano Piloto. No período em que não está na escola ou realizando atividades extras, também ofertadas pela escola - como atendimento em Altas Habilidades (desenho), Laboratório de Aprendizagem e Escola Parque -, fica na

2 Uma discussão mais ampla sobre dificuldades de aprendizagem e a multiplicidade de fatores associados pode ser vista em Rossato \& Mitjáns Martínez (2011).

3 Embora à época da pesquisa a Lei No 11274/2006, PL 144/2005, a Lei 11.114/2005, o Parecer CNE/CEB No 6/2005, a Resolução CNE/CEB N ${ }^{\circ} 3 / 2005$ e o Parecer CNE/CEB № 18/2005 já previssem o Ensino Fundamental de nove anos, alterando a nomenclatura de série para ano, na escola em que a pesquisa foi realizada essa mudança ainda não havia sido adotada, permanecendo a nomenclatura série. 
casa de uma pessoa conhecida da família esperando a mãe sair do trabalho. Da parte da mãe, João é filho único; não conhece pessoalmente seu pai biológico nem seus irmãos que moram fora de Brasília, conversam apenas por telefone, esporadicamente. As dificuldades registradas nos documentos da escola e expressas pela professora no momento inicial da pesquisa referiam-se à resolução de problemas e à interpretação e produção escrita, além de problemas de relacionamento com os colegas.

Fernanda, conforme sua documentação escolar, iniciou a $1^{\text {a }}$ série em 2004, com sete anos de idade. Por dois anos seguidos cursou a $2^{\mathrm{a}}$ série e, por mais dois anos seguidos, a $3^{a}$ série. Em 2009 frequentou a $4^{a}$ série, então com 12 anos de idade, apresentando dois anos de defasagem na relação idade-série. Está na escola onde a pesquisa foi realizada desde 2006 e nos anos anteriores esteve em duas escolas diferentes. Fernanda é negra e, desde 2004, mora num abrigo para crianças, com um irmão mais novo, por terem sido retirados judicialmente da guarda da mãe. Visita a mãe e os irmãos menores, que moram com a mãe, em alguns finais de semana. Durante a semana, nos horários em que não está na escola, faz balé duas vezes por semana e frequenta a Escola-Parque uma vez por semana. Nos demais períodos, Fernanda fica no abrigo, onde estuda, faz tarefas da escola e algumas atividades domésticas, todas supervisionadas por sua responsável legal. As dificuldades reconhecidas pela escola - constantes na documentação e referidas pela professora no início da pesquisa - concentravam-se em Língua Portuguesa e em disciplinas curriculares que exigiam leitura e compreensão de textos - como Ciências, Geografia e História.

Daniel, conforme a documentação escolar, iniciou a $1^{\text {a }}$ série em 2006, com sete anos de idade; frequentou a $2^{a}$ série em 2007 e, no ano de 2008, momento em que a pesquisa foi iniciada, estava frequentando a $3^{a}$ série, sempre na mesma escola. Reside numa região administrativa próxima do Plano Piloto, de onde a mãe o leva de carro próprio para frequentar a escola. Mora com seu pai e sua mãe, ambos profissionais liberais, e uma irmã mais velha. Nos relatórios das séries anteriores, apesar da aprovação como resultado final em todos os anos, encontramos registros de dificuldades em Matemática e Língua Portuguesa, ambas as áreas também apontadas pela professora no início da pesquisa, associadas a falta de atenção na realização das atividades, falta de responsabilidade com as atividades de casa e resistência em rever seus erros.

\section{Instrumentos}

Todos os instrumentos foram elaborados especialmente para essa pesquisa considerando as particularidades dos seus participantes, sendo utilizados como indutores da expressão do outro na produção das informações, e não como fonte de dados. Como instrumentos da pesquisa foram utilizados os numerados e descritos a seguir.
1. Sistemas Conversacionais: permitem ao pesquisador deslocar-se da posição de quem pergunta, como realizado nas entrevistas, e produzir uma dinâmica com um clima favorável para a informação; foram realizados com professores, a direção, a equipe pedagógica e familiares dos estudantes;

2. Instrumentos apoiados em indutores não escritos, cujo uso facilita a expressão de informações singulares, principalmente quando se trata de crianças; podem ser enriquecidos com elementos produzidos a partir de outros instrumentos; foram utilizados desenhos, histórias interativas, completamento oral de frases ilustradas, construção da linha da vida escolar;

3. Instrumentos apoiados em indutores escritos - usados com o objetivo de oportunizar a expressão dos participantes; porém, por serem estudantes que apresentavam certa resistência à escrita, foi utilizada apenas uma redação descritiva sobre como se percebiam na escola e um completamento de frases;

4. Momentos informais - que foram definidos tanto a partir das relações espontâneas com os participantes quanto em decorrência da interação com os instrumentos da pesquisa, pelos indutores diretos e indiretos ali contidos;

5. Análise documental: os documentos (pasta do estudante com documentos relativos à sua história escolar e fichas do conselho de classe) foram utilizados como fonte de informação na caracterização do sujeito;

6. Observação: foi utilizada como recurso para perceber o movimento dos sujeitos na relação com o outro (professores expressando suas opiniões sobre os estudantes, professores conversando com estudantes, reação dos estudantes diante da postura assumida pelo professor a seu respeito, reação dos estudantes diante da postura assumida pelo professor diante dos colegas, reação dos estudantes na ausência dos professores, reação dos estudantes junto aos colegas da escola, estudantes expressando sua opinião sobre os professores, etc.), levantando ou reforçando indicadores formulados no processo da pesquisa.

\section{Procedimentos}

Diante da análise das informações de cada instrumento, foram produzidos indicadores que, no confronto com os indicadores produzidos em outros instrumentos, geraram hipóteses que foram sendo confrontadas com a produção dos pesquisadores em momentos diversos da pesquisa. Um indicador, na Epistemologia Qualitativa, constitui-se de 
momentos que adquirem significação pela interpretação do pesquisador. Não é uma categoria para ser usada como referência, com finalidade descritiva, e não tem relação direta com os elementos tomados em separado, mas ganha significado pela relação que o pesquisador é capaz de estabelecer com outros conjuntos de elementos identificados a partir dos instrumentos utilizados, produzindo hipóteses.

A criação das hipóteses, em confronto com a teoria geral do pesquisador, produziu núcleos teóricos de análise integrados ao processo geral de construção do conhecimento, dentro de uma lógica configuracional que esteve orientada pelas relações dos pesquisadores com o problema estudado. Esse confronto foi contínuo durante a pesquisa e serviu para sinalizar a necessidade de reformular hipóteses, para reconstruir alguns núcleos teóricos de análise já elaborados e mesmo para reformular os indutores de alguns instrumentos. Os resultados serão orientados pelo modelo construtivo-interpretativo em que as informações (dados) não têm valor por si mesmas, mas adquirem solidez pela interpretação do pesquisador, resultante do processo de construção de indicadores e hipóteses em confronto com sua teoria geral.

\section{Resultados e discussões}

Os fundamentos da Epistemologia Qualitativa (González Rey, 2002, 2003a, 2005), descritos anteriormente, dão suporte ao modelo de pesquisa qualitativa adotado. O material empírico produzido no campo não é portador de uma verdade contida nele mesmo, que ganhe legitimidade pela sua descrição; ao contrário, trata-se da construção de modelos teóricos sobre a informação produzida dando visibilidade a um nível ontológico não acessível à observação imediata. É por meio da "construção teórica de sentidos subjetivos e de configurações subjetivas envolvidas nos diferentes comportamentos e produções simbólicas do homem" (González Rey, 2005, p. 116) que os resultados da pesquisa podem ser expressos.

Os resultados apresentados a seguir são construções da trajetória escolar e das relações com diversos grupos sociais dos quais fazem parte os três participantes da pesquisa - João, Fernanda e Daniel -, expressão do movimento da subjetividade no processo de superação das dificuldades de aprendizagem escolar. A análise dos casos foi um recorte de tempo da história de cada um dos participantes, onde fios do passado foram alçados para serem entretecidos com o presente, gerando um espaço dialógico em que os sentidos subjetivos produzidos nesse tempo em movimento puderam emergir. No processo construtivo-interpretativo de análise foram identificados dois eixos explicativos do movimento da subjetividade no processo de superação das dificuldades de aprendizagem: (a) a constituição do sujeito no confronto com o outro; (b) a mudança na personalidade gerada pelas reconfigurações subjetivas e o impacto na produção qualitativa de sentidos subjetivos.
Em primeiro lugar, a constituição do sujeito no confronto com o outro se mostrou central nos processos de aprendizagem escolar dos participantes da pesquisa, demarcando o espaço do outro (mais experiente) no processo de aprendizagem e desenvolvimento humano. Nos três casos investigados, o movimento da subjetividade identificado no período em que a aprendizagem dos estudantes apresentou-se próxima ao esperado pela escola esteve relacionado aos sentidos subjetivos produzidos na relação com o outro. No caso de João, esse outro foi representado pela professora Ana e pela mãe; no caso de Fernanda e Daniel, o outro foi representado pela professora Rosane. Nos três casos analisados, o outro, em circunstâncias distintas, gerou emoções que possibilitaram a produção de sentidos subjetivos mobilizadores dos sujeitos. A simples presença do outro não garante a produção de sentido subjetivo, ao contrário, o outro tem importância no desenvolvimento pela qualidade dos sentidos subjetivos que é capaz de produzir, pois os sentidos subjetivos se produzem na geração do espaço simbólico-emocional particular em cada sujeito (Mitjáns Martínez, 2005).

As mudanças na condição de sujeito foram identificadas em dois dos participantes da pesquisa como resultantes da reconfiguração da natureza dos sentidos subjetivos produzidos no confronto com o outro, diante dos novos arranjos relacionais que se constituíram na dinâmica entre os estudantes. No caso de João, a mãe, por orientação da orientadora educacional da escola, parou de confrontá-lo quanto aos sentimentos em relação ao seu pai biológico, respeitando a emocionalidade produzida por ele. Este fato desencadeou a produção de sentidos subjetivos em relação ao outro que possibilitaram um processo de reaproximação com a mãe e com outras pessoas da escola das quais antes insistentemente mantinha distância. Os sentidos subjetivos que passou a produzir na relação com a orientadora educacional e com a nova professora impactaram profundamente os sentidos subjetivos da aprendizagem escolar. No meio do primeiro ano da investigação houve uma mudança estrutural na escola para receber um estudante com comportamento atípico, e João, por já ter um histórico escolar com problemas de comportamento, foi remanejado para outra turma. Essa nova professora foi quem, pela primeira vez desde que João chegara à escola, levantou a hipótese de que ele poderia ter altas habilidades para o desenho e que esse seria seu recurso principal de aprendizagem, ao contrário do rótulo de dificuldades de aprendizagem que lhe era atribuído.

A dinâmica relacional estabelecida com sua professora no primeiro ano da investigação foi a fonte dos sentidos subjetivos favorecedores da aprendizagem escolar de Fernanda. Essa professora não a via com piedade pela sua história de vida, mas como alguém que precisava se desenvolver com autonomia, já que não poderia contar com o apoio de sua família; via nela alguém que precisava desenvolver recursos psicológicos para enfrentar a vida sozinha, que precisava se constituir como sujeito de sua aprendizagem e desenvolvimento. A produção dos sentidos subjetivos segue desdobramentos e entrelaçamentos que nunca são 
universais, mas que posicionam a pessoa como sujeito de seu próprio desenvolvimento, e, nesse sentido, o outro tem importância para o desenvolvimento quando se converte em uma fonte de produção de sentido subjetivo, numa relação dialógica (González Rey, 2004a). A conquista do reconhecimento da condição de sujeito, identificada em João e Fernanda, ocorre quando a pessoa adquire condições de definir seus objetivos de vida e é capaz de segui-los por meio de sua atividade volitiva com independência, criatividade e congruência (González Rey, 1995).

No caso de Daniel, uma mudança de atitude da professora, no final do primeiro ano da pesquisa, diante da informação de que estaria vivenciando problemas familiares, gerou um novo espaço simbólico-emocional entre ambos: a professora diminuiu o nível de exigência e passou a valorizar mais suas produções e, com isso, Daniel passou a sentir-se acolhido pela professora, ou seja, passou a produzir sentidos subjetivos favoráveis à sua aprendizagem, reconhecendo nela uma ensinante capaz de perceber seu potencial. O tempo de convivência nessa nova dinâmica relacional, desencadeadora da produção de sentidos subjetivos favorecedores da aprendizagem escolar, foi de apenas três meses, pois, com a mudança de professora na passagem de ano, as supostas dificuldades de aprendizagem voltaram a existir. Esse fato demonstra que as mudanças precisam adquirir certa estabilidade para que caracterizem reconfigurações no sistema subjetivo. A tentativa de construir uma identidade de sujeito da aprendizagem foi interrompida quando se rompeu a dinâmica simbólico-emocional produtora dos novos sentidos subjetivos que sustentavam a aprendizagem escolar.

O sujeito é uma confluência das configurações subjetivas constituídas em sua história que expressam a produção simbólico-emocional de cada pessoa. O pensamento, a reflexão e as decisões dão legitimidade ao sujeito singular, possibilitando-lhe integrar a complexidade da vida social sem perder a capacidade de continuar gerando espaços próprios de subjetivação (González Rey, 2005, 2006, 2007). Essa possibilidade de geração de espaços próprios de subjetivação foi identificada em João e Fernanda, mas, como vimos anteriormente, não foi identificada em Daniel.

Em segundo lugar, o outro eixo de análise pauta-se pela mudança na personalidade gerada pelas reconfigurações subjetivas e o impacto na produção qualitativa de sentidos subjetivos. Vale destacar que os sentidos subjetivos são irrepetíveis, ou seja, sempre são novas produções, por isso imprimimos o termo qualitativo para demarcar a importância dessas produções. As configurações subjetivas caracterizam-se pela possibilidade de integrar elementos dinâmicos e contraditórios, os quais podem converter-se em sentidos subjetivos dominantes. González Rey (1995, 2004a) destaca alguns desses elementos que podem estar implicados nas reconfigurações subjetivas, tornando-as potencialmente mobilizadoras do sistema subjetivo, elementos que, na pesquisa realizada, foram analisados pelas informações do campo empírico.

O primeiro elemento é a qualidade das formas e sentidos sociais e culturais das atividades, já que muitas delas são movidas pela automação gerada pela rotina criada na vida das pessoas. A diferença entre os dois tipos de ação é determinada pela influência do momento de vida das pessoas e pelos sentidos subjetivos produzidos diante das formas e sentidos sociais que as ações assumem na realidade individual; ou seja, os sentidos subjetivos das ações e relações, produzidos no confronto entre a subjetividade individual e a subjetividade social, são marcados pela organização simbólico-emocional de cada sujeito. No caso de Fernanda, o sentido subjetivo produzido na relação com a professora - que considerou sua entrada na adolescência e o fato de não poder contar com uma família que a apoiasse em seu desenvolvimento -, gerou condições para que Fernanda se constituísse independentemente de suas condições familiares, possibilitando reconfigurações que abriram caminhos para seu desenvolvimento subjetivo. Os sentidos subjetivos produzidos na convivência com a professora reconfiguraram subjetivamente seu sistema de autovaloração, possibilitando a consolidação de uma identidade até então muito frágil, resultante dos sentidos subjetivos produzidos diante das histórias de abandono e rejeição por ela vividas. O caso de João também é ilustrativo dessa condição para o desenvolvimento: o sujeito João deixou de integrar a subjetividade social da escola como um estudante com dificuldades e problemas de comportamento, um estudante que não é morador da quadra 4 e passou para o grupo de elite da escola, como um estudante que tem altas habilidades, o que, sem dúvida, no confronto com a subjetividade individual, possibilitou a produção de novos sentidos subjetivos favorecedores de seu desenvolvimento subjetivo.

A questão da temporalidade é de extrema importância para pensar numa reconfiguração subjetiva, uma vez que, como já vimos, a mudança se dá num contínuo movimento de ordem/desordem/interações-reencontros/organização, principalmente no que se refere à relação entre os sentidos subjetivos e as configurações subjetivas. As relações e ações do sujeito em desenvolvimento vão modificando seu sentido psicológico ao longo do tempo. O caso de Daniel é ilustrativo de como o rompimento de uma emocionalidade pode interromper um processo de mudança, ao contrário do que ocorreu com Fernanda e João, que, mesmo quando as condições passaram a ser outras - novas professoras no ano de 2009 - as reconfigurações que movimentaram o desenvolvimento continuaram ativas.

O sentido subjetivo não conscientizado pelo sujeito é o terceiro elemento que merece destaque no processo de reconfiguração subjetiva, pois muitos dos sentidos subjetivos produzidos nas ações e relações não são conscientizados pelo sujeito nem são movidos pela intencionalidade do outro. O outro pode criar situações que envolvam emocionalmente o sujeito, mas não pode controlar o que vai

4Referente às quadras do Plano Piloto, Brasília-DF. João morava numa das regiões administrativas - RA e deslocava-se para o Plano Piloto junto com a mãe, que trabalha numa das residências da quadra onde fica localizada a escola. Destaca-se que os moradores das quadras geralmente possuem condições sócias econômicas significativamente superiores às dos moradores das RAs. 
ser produzido subjetivamente por ele. O caso de João, por exemplo, demonstrou que a produção de sentidos subjetivos não é conscientizada pelo sujeito. João conseguia identificar a emocionalidade gerada diante da negação do pai biológico pela sua família, mas não os sentidos subjetivos que eram produzidos nessas relações, e isto gerava a rejeição do outro. A emocionalidade produzida pelo sujeito pode ser conscientizada por ele, diferentemente dos sentidos subjetivos das ações e relações, não sendo possível, inclusive, diferenciar se foram positivos ou negativos, nem conhecer os desdobramentos gerados nas configurações subjetivas diante do confronto com sentidos subjetivos produzidos em outras ações e relações.

As formações motivacionais complexas podem participar do desenvolvimento por se constituírem como uma integração de sentidos subjetivos direcionados a uma ação reflexiva e intencional do sujeito, compondo o quarto elemento presente no processo de reconfiguração subjetiva. As motivações de Fernanda em torno de uma vida independente, as motivações de Daniel em satisfazer o pai e as motivações de João para conquistar a valorização dos seus desenhos foram mobilizadores da produção de sentidos subjetivos de diferentes procedências que integraram suas respectivas configurações subjetivas. Projetivamente, poder-se-ia inferir que a temporalidade é um fator considerável na organização de uma nova configuração subjetiva pela ordem/desordem/ interação/organização necessária à ocorrência da mudança.

O último elemento destacado refere-se ao alto nível de individualização do sujeito, expresso em sua iniciativa e criatividade. O pensamento, a reflexão e as decisões tomadas pelo individuo singular legitimam sua condição de sujeito e possibilitam que entre na dinâmica complexa da vida social e seja capaz de gerar espaços próprios de subjetivação. Fernanda passou a perceber suas qualidades de sujeito e investir mais nelas, e João passou a reconhecer no outro a possibilidade de produzir espaços de ação subjetivada. Por meio dos casos analisados, evidenciou-se que as mudanças subjetivas se convertem em desenvolvimento quando integram a organização das configurações subjetivas e geram novos caminhos para que outras mudanças aconteçam.

Os três casos analisados permitiram sistematizar uma compreensão do desenvolvimento da subjetividade, destacando-se a importância da produção contínua e irrepetível dos sentidos subjetivos, tanto na constituição do sujeito como nas reconfigurações subjetivas que se integram na personalidade. A produção de novos sentidos subjetivos, tomada na centralidade do processo de desenvolvimento da subjetividade, apresenta-se como uma possibilidade de rompimento com o determinismo humano e com a personalidade fixa. Embora sujeito e personalidade sejam constituidores da subjetividade individual, a subjetividade social não está isenta desse processo, ao contrário, o sujeito se integra à subjetividade social gerando novos focos de subjetivação, não de forma intencional e direta, mas de um momento no movimento de um sistema complexo, que não responde de maneira direta nem linear à intencionalidade humana.
O confronto do sujeito com a subjetividade social traduz-se num espaço gerador de conteúdos simbólico-emocionais produtores de sentidos subjetivos, demarcando a constituição do sujeito numa matriz relacional. As experiências vividas pelo sujeito produzem uma variedade de sentidos subjetivos que alimentam e desenvolvem as configurações subjetivas, as quais, mesmo diante dessa mobilidade, mantêm núcleos estáveis de produção subjetiva. Os núcleos, organizados pelos sentidos subjetivos dominantes, dão integridade à configuração, onde um novo sentido subjetivo, que assuma papel dominante, pode mobilizar mudanças no núcleo de uma configuração.

Em dois participantes da pesquisa, João e Fernanda, o movimento da subjetividade, pela complexidade envolvida nas mudanças subjetivas e pela relativa estabilidade adquirida na organização do sistema, possibilitou o desenvolvimento da subjetividade necessário à superação das dificuldades de aprendizagem; portanto, quanto a Fernanda e João, podemos afirmar que a superação das dificuldades de aprendizagem decorrentes do desenvolvimento da subjetividade envolveu uma reorganização estável da personalidade e das qualidades do sujeito, assumindo novos níveis qualitativos de organização subjetiva. No caso de Daniel, o movimento da subjetividade não chegou a gerar mudanças complexas que ganhassem estabilidade durante o período investigado, uma vez que, quando a emocionalidade produtora dos sentidos subjetivos se rompeu, houve também uma involução na qualidade que acreditávamos ter alcançado sua aprendizagem. O caso de Daniel mostra que, no momento em que a emocionalidade geradora de uma mudança se interrompe, pode haver involução nos níveis de organização subjetiva que se anunciavam até então, demonstrando que os sentidos subjetivos precisam de certo tempo, estabilidade e intensidade para se integrarem às configurações subjetivas e provocarem mudanças mais complexas.

\section{Considerações finais}

Ao final desse artigo, como contribuição teórica, defendemos que a superação das dificuldades de aprendizagem requer o desenvolvimento da subjetividade. Definimos o desenvolvimento da subjetividade como mudanças subjetivas que impactam e que ganham certa estabilidade, sendo capazes de desencadear outras mudanças e gerar novos níveis qualitativos de organização subjetiva. A análise do desenvolvimento da subjetividade requer adentrar no movimento contínuo de produção de sentidos subjetivos para identificar os impactos, as rupturas e as construções que estes são capazes de desencadear no sujeito.

No tocante às dificuldades de aprendizagem, estas ocorrem a partir da negação do sujeito do aprender, da ausência de condições que favoreçam a produção de sentidos subjetivos capazes de promover a aprendizagem escolar a partir da existência de configurações subjetivas geradoras de danos que comprometem a produção de sentidos subjetivos favoráveis ao aprender escolar. O contexto de análise 
da superação das dificuldades é muito mais amplo do que os problemas expressos pelos estudantes no contexto escolar, pois há um sistema subjetivo envolvido. A superação requer uma reorganização subjetiva dos sentidos que, de alguma forma, estejam vinculados à aprendizagem escolar.

Como contribuição prática, produzimos um olhar que permite compreender as dificuldades de aprendizagem de um modo que extrapola a mera ação cognitiva do estudante. A análise apresentada neste artigo coloca em discussão o trabalho desenvolvido pelas escolas diante das dificuldades de aprendizagem, que muitas vezes se constituem em mais do mesmo, desconsiderando a complexidade de um problema que extrapola o espaço de ação do estudante. As ações dos professores que desencadearam as mudanças subjetivas que, por sua vez, impactaram a aprendizagem dos estudantes, não foram planejadas e intencionais, mas poderiam tê-lo sido. Os casos relatados na pesquisa revelam a importância dos processos subjetivos envolvidos no ensinar e no aprender. São ações pedagógicas que promovem a constituição e o reconhecimento do sujeito e possibilitam aos estudantes experiências simbólico-emocionais produtoras de sentidos subjetivos favorecedores da aprendizagem escolar. Consideramos, por fim, que os conhecimentos produzidos podem ser significativos para os programas de formação de professores, para a formulação de propostas pedagógicas para as escolas, para a proposição de políticas públicas, entre outros fins.

\section{Referências}

González Rey, F. (1995). Comunicación personalidad y desarrollo. Ciudad de La Habana, Cuba: Editorial Pueblo y Educación.

González Rey, F. (2002). Pesquisa Qualitativa em Psicología: caminhos e desafios. São Paulo: Pioneira Thompson Learning.

González Rey, F. (2003a). Sujeito e subjetividade: uma aproximação histórico-cultural. São Paulo: Pioneira Thomson Learning.

González Rey, F. (2003b). Epistemología Cualitativa y Subjetividad. São Paulo: EDUC.

González Rey, F. (2004a). O sujeito, a subjetividade e o outro na dialética complexa do desenvolvimento humano. Em L. M. Simão
\& A. Mitjáns Martínez (Eds.), O outro no desenvolvimento humano (pp. 1-27). São Paulo: Pioneira Thompson Learning.

González Rey, F. (2004b). O social na psicologia e a psicologia social: a emergência do sujeito. Petrópolis, RJ: Vozes.

González Rey, F. (2005). Pesquisa Qualitativa e Subjetividade: os processos de construção da informação. São Paulo: Pioneira Thomson Learning.

González Rey, F. (2006). O sujeito que aprende: desafios do desenvolvimento do tema da aprendizagem na psicologia e na prática pedagógica. Em M. C. Tacca (Ed.), Aprendizagem e trabalho pedagógico (pp. 29-44). Campinas, SP: Alínea.

González Rey, F. (2007). Psicoterapia, Subjetividade e PósModernidade. Uma aproximação histórico-cultural. São Paulo: Pioneira Thomson Learning.

González Rey, F. (2008). Subjetividad social, sujeto e representaciones sociales. Perspectivas em Psicologia, 4(2), 225-243.

Mitjáns Martínez, A. (2005). A Teoria da Subjetividade de González Rey: uma expressão do paradigma da complexidade na Psicologia. Em F. González Rey (Ed.), Subjetividade, Complexidade e Pesquisa em Psicologia (pp.1-26). São Paulo: Pioneira Thomson Learning.

Morin, E. (2003a). O método - 1. A natureza da natureza. Porto Alegre: Sulina.

Morin, E. (2003b). O método - 5. A humanidade da humanidade. Porto Alegre: Sulina.

Morin, E., Ciurama, E., \& Motta, R. D. (2003). Educarna era planetária: O pensamento complexo como método de aprendizagem pelo erro e incerteza humana. São Paulo: Cortez; Brasília: UNESCO.

Rossato, M., \& Mitjáns Martínez, A. (2011) A superação das dificuldades de aprendizagem e as mudanças na subjetividade. Em A. Mitjáns Martínez \& M. C. V. Tacca (Eds.), Possibilidades de aprendizagem: ações pedagógicas para alunos com dificuldade $e$ deficiência (pp. 71-107). Campinas, SP: Alínea. 
Recebido em: 01/06/2012

Reformulado em:13/12/2012

Aprovado em: 23/01/2013

\section{Sobre as autoras}

Maristela Rossato (stelarossato@hotmail.com)

Endereço: Condomínio Mansões Entre Lagos, Etapa 4, Conjunto H, Casa 8 Sobradinho,

Brasília - DF, CEP 73225-903.

Albertina Mitjáns Martínez (amitjans@terra.com.br)

Endereço: SQS 407, Bloco R, Apto 206, Brasília - DF, CEP 70258-180

Trabalho derivado da Tese de Doutorado "O movimento da subjetividade no processo de superação das dificuldades de aprendizagem escolar". As discussões sobre dificuldades de aprendizagem foram publicadas em Rossato, M., \& Mitjáns Martínez, A. (2011). A superação das dificuldades de aprendizagem e as mudanças na subjetividade. Em A. Mitjáns Martínez \& M. C. V. Tacca (Eds.), Possibilidades de aprendizagem: ações pedagógicas para alunos com dificuldade e deficiência (pp. 71-107). Campinas, SP: Alínea. 